\title{
Clinical, imagiological and etiological spectrum of posterior reversible encephalopathy syndrome
}

\author{
Espectro clínico, imagiológico e etiológico da síndrome de encefalopatia posterior reversível \\ P Ricardo Pereira ${ }^{1}$ João Pinho², Margarida Rodrigues², João Rocha ${ }^{2}$, Filipa Sousa², José Amorim³, \\ Manuel Ribeiro ${ }^{3}$, Jaime Rocha ${ }^{3}$, Carla Ferreira ${ }^{2}$
}

\begin{abstract}
Objective: Analyze the cases of posterior reversible encephalopathy syndrome (PRES) admitted in a Neurology Department during an 8-year period. Method: Retrospective observational study in a central hospital in the north of Portugal. Results: 14 patients were identified, mean age 52.3 years. Precipitating factors included: eclampsia, isolated arterial hypertension, spinal trauma and autonomic dysreflexia, Guillain-Barré syndrome, sepsis, sarcoidosis and pulmonary cryptococcosis and drugs. Most patients presented posterior-predominant vasogenic edema lesions, however $64.2 \%$ presented frontal lesions and in $42.8 \%$ cerebellum was involved. Four patients also had acute ischemic lesions and 1 had hemorrhagic lesions. During follow-up 10 patients recovered fully, 2 recovered partially, 1 suffered a recurrence and 2 died in hospital. Conclusion: PRES has many etiological factors. The terms posterior and reversible should be revised because PRES frequently involves other brain regions and it is not always reversible. PRES patients may develop life-threatening complications and mortality is not negligible.
\end{abstract}

Keywords: posterior reversible encephalopathy syndrome, vasogenic edema, arterial hypertension.

RESUMO

Objetivo: Análise dos casos de síndrome de encefalopatia posterior reversível (PRES) internados em um Serviço de Neurologia durante oito anos. Método: Estudo restrospectivo observacional num hospital central do norte de Portugal. Resultados: Identificaram-se 14 casos, idade média de 52,3 anos. Os factores precipitantes foram: eclâmpsia, hipertensão arterial isolada, traumatismos vertebro-medulares com disfunção autonómica, síndrome de Guillain-Barré, sépsis, sarcoidose e criptococose pulmonar e fármacos. A maioria dos doentes apresentou lesões edematosas de predomínio posterior, contudo 64,2\% apresentaram lesões frontais e 42,8\% apresentaram também lesões cerebelosas. Quatro doentes tinham lesões isquémicas agudas e um apresentou lesões hemorrágicas. Durante o seguimento, 10 doentes recuperaram totalmente, 2 recuperaram com sequelas, 1 teve recidiva e 2 faleceram durante o internamento. Conclusão: A PRES apresenta muitos factores precipitantes. As designações posterior e reversivel deverão ser reequacionadas dado que a PRES afecta outras zonas do cérebro e nem sempre é reversível, apresentado complicações e mortalidade não negligenciáveis.

Palavras-chave: síndrome de encefalopatia posterior reversivel, edema vasogénico, hipertensão arterial.

Posterior reversible encephalopathy syndrome (PRES) was initially described in patients presenting with sudden onset headache, mental status changes, visual disturbances and seizures associated with a predominantly posterior leukoencephalopathy ${ }^{1}$. Reversibility and posterior region predominance of lesions were main features in its original description. The first reported cases were mainly related to arterial hypertension (hypertensive encephalopathy), hypertension in pregnancy (namely eclampsia) and immunosuppressive therapy ${ }^{1,2}$. PRES is an increasingly recognized syndrome and since its original description other series have been published ${ }^{3}$, presenting cases with atypical features and revealing new causes and associated conditions (inflammatory or auto-immune diseases, systemic inflammatory response syndrome, electrolyte imbalances, spinal injuries, Guillain-Barré syndrome (GBS), vasoactive drugs,

\footnotetext{
'Departamento de Medicina Interna, Unidade Local de Saúde de Matosinhos, Hospital Pedro Hispano, Matosinhos, Portugal;

2Departamento de Neurologia, Hospital de Braga, Braga, Portugal;

${ }^{3}$ Departamento de Neuroradiologia, Hospital de Braga, Braga, Portugal.

Correspondence: P Ricardo Pereira; Hospital Pedro Hispano; Rua Dr. Eduardo Torres, 4464-513; Senhora da Hora, Matosinhos, Portugal;

E-mail: p.ricardo.o.pereira@gmail.com

Conflict of interest: There is no conflict of interest to declare.

Received 16 April 2014; Received in final form 05 September 2014; Accepted 25 September 2014.
} 
chemotherapy agents and monoclonal antibodies) $)^{3,4}$. PRES pathophysiology remains unclear, but cerebral autoregulation impairment as well as endothelial dysfunction are proposed to be the most important underlying mechanisms ${ }^{5}$. Neuroimaging has a major role in the diagnosis of this entity ${ }^{6,7}$. MRI is the best exam to diagnose PRES although CT is also useful. Lesions are usually located in the parieto-occipital region sparing calcarine and paramedian regions of the occipital lobe. Nevertheless, there may be lesions in the frontal lobe, cerebellum and diencephalon. Based on their location, four topographic patterns were described: mainly parietaloccipital pattern, superior frontal sulcus pattern, holohemispheric watershed pattern, and partial or asymmetric expression of the primary patterns ${ }^{8}$. PRES usually has a benign prognosis and is reversible after correction or removal of the precipitating factor and blood pressure control ${ }^{1,2}$.

The aim of this paper is to review our series of patients with PRES, comparing clinical, imagiological and etiological aspects with previous literature.

\section{METHOD}

Retrospective and descriptive study developed in a central hospital in the north of Portugal. Patient selection and data collection was performed using the electronic patient's database. Patients admitted with the diagnosis of PRES between January 2005 and September 2013 were included in this study. Two cases included were previously reported ${ }^{9}$. The criteria of inclusion were: (1) acute or subacute neurologic syndrome characterized by seizures, encephalopathy, headache, visual disturbance or focal deficit; (2) neuroimaging findings consistent with the diagnosis of PRES, namely otherwise unexplained focal or diffuse vasogenic edema lesions. Patients with edematous lesions secondary to ischemic, hemorrhagic, infectious, inflammatory or spaceoccupying lesions were excluded. Hypertension was defined as a systolic blood pressure of $140 \mathrm{mmHg}$ or greater and/or a diastolic blood pressure of $90 \mathrm{mmHg}$ or greater.

Clinical and radiological files were systematically analyzed and the following variables were recorded: gender, age, signs and symptoms, blood pressure at admission, lesions topography in brain imaging, presence of ischemic and hemorrhagic lesions, etiological factors, association with previous cardiovascular risk factors, complications, recurrences and mortality. This study was conducted according to local Ethics Committee requirements.

\section{RESULTS}

Fourteen patients were included ( $57 \%$ males), mean age was 52.3 years (20-89). Half of the patients presented with
Table 1. Clinical manifestations during the course of disease.

\begin{tabular}{lc}
\hline & $\mathrm{N}$ \\
\hline Encephalopathy & 11 \\
Seizures & 10 \\
Visual disturbances & 9 \\
Headache & 5 \\
Focal neurologic deficit $>24 \mathrm{~h}$ & 4 \\
Focal neurologic deficit $<24 \mathrm{~h}$ & 2 \\
\hline
\end{tabular}

$\mathrm{N}$ : Number of cases.

seizures (7/14), three patients with headaches, three with visual disturbances (visual hallucinations, campimetric deficits and cortical blindness with Anton syndrome) and one patient presented with focal motor deficit. Table 1 displays clinical manifestations in the course of the disease of all patients. Most patients (13/14) had high blood pressure on admission: mean systolic pressure (sBP) was $172.6 \mathrm{mmHg}$ (111-206), mean diastolic pressure (dBP) was $92.2 \mathrm{mmHg}$ (64-121) and mean mean blood pressure (mBP) was $109.1 \mathrm{mmHg}$ (80-149). Four patients had previous history of hypertension. The only patient presenting with normal blood pressure had a spinal trauma with autonomic dysfunction. Regarding other cardiovascular risk factors, 5 patients had dyslipidemia, 4 patients had diabetes and 2 patients were smokers. Six patients presented more than one risk factor simultaneously.

Thirteen patients performed MRI. In one patient, diagnosis was supported exclusively by brain CT. Two patients had no abnormalities in CT, but subsequent MRI revealed findings suggestive of PRES. Table 2 shows brain lesions characteristics found in these patients. The majority of patients presented lesions in other locations besides the posterior parietooccipital region and in $3 / 14$ patients this region was not predominantly affected. Almost one third of patients presented ischemic or hemorrhagic lesions. Figure shows the main radiological findings. Seven patients performed video electroencephalogram and among those 6 had slowing of background activity, localized or generalized slowing of activity, suggesting encephalopathic cortical dysfunction.

Table 2. Radiological characteristics of brain lesions.

\begin{tabular}{lc}
\hline & $\mathrm{N}$ \\
\hline Location & \\
Parieto-occipital predominance & 11 \\
Frontal lesions & 9 \\
Cerebellar lesions & 6 \\
Cortical lesions & 13 \\
Subcortical lesions & 14 \\
Other features & 4 \\
Acute ischemic lesions & 1 \\
Parenchymal hemorrhage & 0 \\
Angiography changes* & \\
\hline *Angiographic study was performed in 5 patients using MRI. N: Number of \\
cases.
\end{tabular}



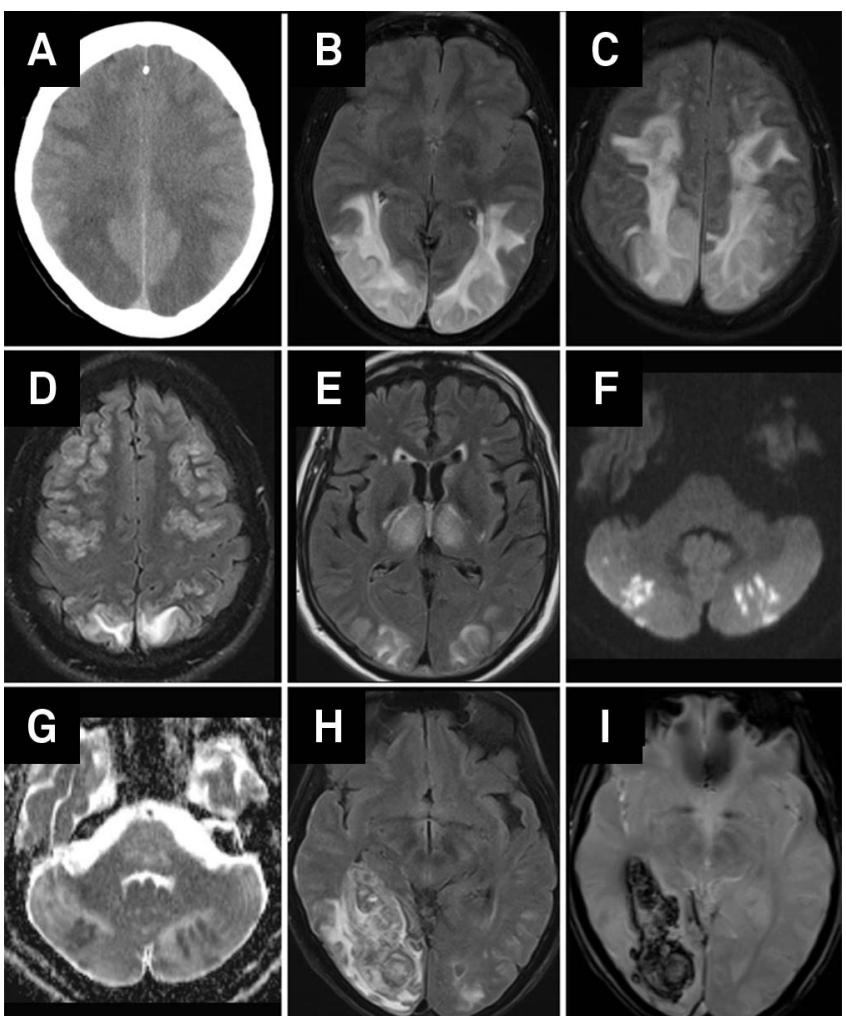

Figure. PRES radiological characteristics. (A) CT, bilateral posterior parietal and frontal cortico and subcortical hypodense lesions; (B) MRI, FLAIR, bilateral temporo-occipital hyperintense lesions; (C-D) MRI, FLAIR, bilateral frontal cortical and subcortical lesions; (E) MRI, FLAIR, typical hyperintense bilateral occipital associated with bilateral thalamic lesions; (F-G) MRI, DWI, multiple bilateral cerebellar lesions presenting restriction to diffusion (recent ischemic lesions); and (H-I) RMI, FLAIR and T2 echo-gradient, revealing typical predominately posterior PRES lesions associated with a right temporooccipital hemorrhage.

Among etiological factors, eclampsia was the most frequent (4 patients), followed by isolated high blood pressure (3 patients) and spinal trauma with autonomic dysfunction (2 patients). Other factors identified were sepsis, sarcoidosis and concomitant pulmonary cryptococcosis, GBS, octreotide perfusion and chemotherapy (Table 3).

Duration of follow-up was variable ( 3 weeks- 8 years). Most patients presented a partial or complete recovery

Table 3. Identified precipitating factors.

\begin{tabular}{ll} 
& N \\
\hline Eclampsia & 4 \\
High blood pressure & 3 \\
Autonomic dysfunction related to spinal trauma & 2 \\
Sepsis & 1 \\
Pulmonary sarcoidosis and cryptococcosis & 1 \\
Guillain-Barré syndrome & 1 \\
Octreotide perfusion & 1 \\
Chemotherapy (Cisplatin, Gemcitabine, Bevacizumab)* & 1 \\
\hline
\end{tabular}

*Hypomagnesemia was also present (cisplatin side effect but also potentially pathogenic). N: Number of cases.
Table 4. Clinical outcome.

\begin{tabular}{lc}
\hline & $\mathrm{N}$ \\
\hline Full recovery & 10 \\
Partial recovery & 2 \\
Recurrence & 1 \\
Death & 2 \\
\hline
\end{tabular}

$\mathrm{N}$ : Number of cases.

(Table 4). Brain MRI was repeated in 8 patients and in seven patients lesions disappeared. Two patients developed neurological sequelae (epilepsy, severe focal motor deficit). Two patients died after onset. One patient developed rapidly progressive bilateral edema and acute ischemic lesions, with mass effect, intracranial hypertension refractory to medical therapy, and died 19 days after admission. The other patient had been submitted to abdominal surgery for gastric cancer, presented with PRES after octeotride perfusion and died of sepsis related to esophago-jejunal anastomosis leak 3 weeks later. One case of recurrence was observed two months after the first event. This patient had a persistent autonomic dysfunction related to spinal trauma.

\section{DISCUSSION}

This study describes the clinical and radiological features of 14 patients with PRES, affecting individuals of all ages. In this series there was a male predominance, although in other series there is a slight female predominance, even when eclampsia associated cases are not taken into account ${ }^{10,11}$. In most patients of our series, the identified causes were those classically described, namely, eclampsia and high blood pressure. Nevertheless, the cases associated with autonomic dysfunction related to spinal trauma, sepsis, sarcoidosis and pulmonary cryptococcosis, GBS and drugs demonstrate the diversity of precipitating factors that culminate in a common clinical-radiological syndrome $e^{3,12,13}$. High blood pressure was present in the majority of patients, supporting the hypothesis of cerebral autoregulation impairment as the main pathogenic mechanism in PRES ${ }^{1,10}$. When cerebral autoregulation capacity is overcome by systemic blood pressure, cerebral hyperperfusion emerges, damaging the blood brain barrier and originating liquid leakage to the extracellular space and vasogenic edema, mainly in arterial border territories ${ }^{1,10,14,15,16}$. The fact that only 4 patients had previous high blood pressure supports the idea that sudden elevation of blood pressure prevents vascular adaptation to take place. The mean $\mathrm{mBP}$ in our patients series $(109 \mathrm{mmHg})$ was inferior to the considered upper limit value of cerebral autoregulation, situated around $150 \mathrm{mmHg}^{17}$. However, Liman et al. ${ }^{11}$ demonstrated that $\mathrm{mBP}$ was not correlated with edema severity, while sBP had a positive correlation with edema severity supporting 
the hypothesis of the acute lesion of the blood-brain barrier. In this series there was only one patient with normal blood pressure, contrasting with other reports where $20 \%-30 \%$ of patients with PRES presented without high blood pressure ${ }^{9}$. The 2 cases related to autonomic dysfunction associated with spinal trauma support the role of the sympathetic nervous system dysfunction in PRES at least in some patients ${ }^{9}$.

In addition to blood pressure, other mechanisms that cause endothelial dysfunction, blood brain barrier impairment and cerebral edema could also be involved, and the cases associated with sepsis, sarcoidosis and drugs may be illustrative of this hypothesis. In this series one patient treated with bevacizumab developed PRES. In fact, there is a growing number of PRES cases occurring in patients treated with anti-vascular endothelial growth factor agent (anti-VEGF) as bevacizumab. This drug interferes with vascular permeability and with endothelium intracellular signaling pathways supporting the endothelial dysfunction role in this disease ${ }^{18}$.

Concerning topography of lesions, most patients presented predominantly posterior parietal-occipital lesions which may be explained by the lower density of sympathetic fibers in the vertebrobasilar territory, making it more susceptible to systemic blood pressure oscillations ${ }^{1,19}$. Nevertheless, $64.2 \%$ presented frontal lobe lesions and $42.8 \%$ also presented cerebellar lesions, in accordance to other series ${ }^{3,10,11,13}$. Thus, posterior in PRES designation may be inadequate. Furthermore, this syndrome was initially described as a white matter disease ${ }^{1}$, but in $92.8 \%$ of our patients, cortical involvement was demonstrated.

It has been suggested that in PRES, arteriolar vasoconstriction occurs in response to cerebral hyperperfusion, thus leading to hypoperfusion, ischemia and subsequent edema ${ }^{10,15,16}$. Although angiographic studies demonstrate focal or diffuse vasoconstriction, ischemic complications are not frequent ${ }^{20}$. Acute ischemic complications occurred in $4 / 14(28.6 \%)$ of our patients, in accordance to what is described in the literature ${ }^{11,16}$. There was only one case of cerebral hemorrhage $\mathbf{7 . 1 \% )}$ in this series. However in the literature, hemorrhagic complications occur in 15 to $32 \%$ of cases, mostly in the form of petechial bleeding ${ }^{11,16}$.
Ten of 14 patients experienced a complete clinical recovery, supporting the reversibility of this syndrome. Follow-up MRI showed partial or complete improvement of brain lesions in 7/8 patients. Liman et al. ${ }^{11}$ reported a partial or complete recovery of lesions in $82 \%$ of patients during follow-up. Recurrent PRES episodes are rare ${ }^{11,13}$, and occurred in $1 / 14$ patient in this series. The adequate control of blood pressure and the elimination of all other precipitating factors should be achieved during acute management and follow-up ${ }^{21}$. Among patients that recovered partially, one developed motor sequelae and the other developed epilepsy. Furthermore, 2 patients (14.3\%) died, and death was attributed directly to PRES in one of them. Rarely this entity may complicate with progressive cerebral edema, intracranial hypertension and death ${ }^{1,10,11}$. Morbidity and mortality in this series $(28.6 \%)$ prove that PRES is not always reversible and benign.

This study had several limitations associated with its retrospective design and related to the population size. Imagiological evaluation was not uniform in all patients and angiographic study was absent in 9/14 patients. Follow-up was not homogeneous, mainly in what concerns to radiological reevaluation. In depth analysis of clinical and analytical variables with prognostic significance was not performed due to the lack of statistical power.

In conclusion, PRES should be rapidly recognized in emergency settings. It is a clinical-radiological entity whose pathophysiology is not fully understood and with a diversity of precipitating factors. The denomination posterior and reversible has its origin in the first description by Hinchey ${ }^{1}$ but the growing number of reported cases, including the present series, show the frequent involvement of other brain regions and less favorable outcomes with significant morbidity and mortality. While pathophysiological mechanisms are not fully understood the current designation remains useful, although it does not encompass its clinical and radiological diversity. PRES, reversible vasoconstriction syndrome and cerebral hyperperfusion syndrome may partially share common pathological mechanisms and they may all belong to a larger spectrum of acquired vasculopathies.

\section{References}

1. Hinchey J, Chaves C, Appignani B, et al. A reversible posterior leukoencephalopathy syndrome. N Engl J Med 1996;334:494.

2. Schwartz R B, Mulkern R V, Gudbjartsson H, Jolesz F. Diffusionweighted MR imaging in hypertensive encephalopathy: clues to pathogenesis. Am J Neuroradiol 1998;19:859-862.

3. Hinchey J. Reversible posterior leukoencephalopathy syndrome: what have we learned in the last 10 years? Arch Neurol 2008;65:175-176

4. Lee VH, Wijdicks EFM, Manno EM, Rabinstein AA. Clinical spectrum of reversible posterior leukoencephalopathy syndrome. Arch Neurol 2008;5:205-210
Bartynski WS. Posterior reversible encephalopathy syndrome, part 2 controversies surrounding pathophysiology of vasogenic edema. AJNR Am J Neuroradiol 2008;29:1043-1049.

6. Bartynski WS. Posterior reversible encephalopathy syndrome, part 1: fundamental imaging and clinical features. AJNR Am J Neuroradiol 2008;29:1036-1042.

7. Lamy C, Oppenheim C, Méder JF, Mas JL Neuroimaging in posterior reversible encephalopathy syndrome. J Neuroimaging 2004;14:89.

8. Bartynski WS, Boardman JF. Distinct imaging patterns and lesion distribution in posterior reversible encephalopathy syndrome. Am J Neuroradiol 2007;28:1320-1327. 
9. Matias AC, Rocha J, Cerqueira ME, Pereira JM. Autonomic dysreflexia and posterior reversible encephalopathy syndrome. Am J Phys Med Rehabil 2013;92:453-458.

10. Stott VL, Hurrell MA, Anderson TJ. Reversible posterior leukoencephalopathy syndrome: a misnomer reviewed. Intern Med J 2005;35:83.

11. Liman TG, Bohner G, Heuschmann PU, Endres M, Siebert E. The clinical and radiological spectrum of posterior reversible encephalopathy syndrome: the retrospective Berlin PRES study. J Neurol 2012;259:155-164.

12. Stevens CJ, Heran MKS. The many faces of posterior reversible encephalopathy syndrome. Br J Radiol 2012;85:1566-1575.

13. Fugate JE, Claassen DO, Cloft HJ, Kallmes DF, Kozak OS, Rabinstein AA. Posterior reversible encephalopathy syndrome: associated clinical and radiological findings. Mayo Clin Proc 2010;85:427-432.

14. Vaughan CJ, Delanty $\mathrm{N}$. Hypertensive emergencies. Lancet 2000;356:411-417.

15. Ito $\mathrm{Y}$, Niwa $\mathrm{H}$, lida $\mathrm{T}$, et al. Post-transfusion reversible posterior leukoencephalopathy syndrome with cerebral vasoconstriction. Neurology 1997;49:1174-1175.
16. Tajima $\mathrm{Y}$, Isonishi K, Kashiwaba T, Tashiro K. Two similar cases of encephalopathy, possibly a reversible posterior leukoencephalopathy syndrome: serial findings of magnetic resonance imaging, SPECT and angiography. Intern Med 1999;38:54-58.

17. Ziai WC, Mirski MA. Blood pressure management in the neurocritical care patient. In: Suarez JI (Ed). Critical care neurology and neurosurgery. New Jersey: Humana Press Inc; 2004:247-266

18. Tlemsani C, Mir O, Boudou-Rouquette P, et al. Posterior reversible encephalopathy syndrome induced by anti-VEGF agents. Targ Oncol 2011;6:253-258.

19. Sheth RD, Riggs JE, Bodenstenier JB, Gutierrez AR, Ketonen LM, Ortiz OA. Parietal occipital edema in hypertensive encephalopathy: a pathogenic mechanism. Eur Neurol 1996;36:25-28.

20. Bartynski WS, Boardman JF. Catheter angiography, MR angiography, and MR perfusion in posterior reversible encephalopathy syndrome. AJNR Am J Neuroradiol 2008;29:447-455.

21. Garg RK. Posterior leukoencephalopathy syndrome. Postgrad Med J 2001;77:24-28. 